\title{
Aplicação metodológica da análise de conteúdo em pesquisas de análise de política externa
}

Methodological Applications of Content Analysis in Foreign Policy Analysis

Aplicación metodológica del análisis de contenido en investigaciones de política exterior

\section{Introdução}

A análise de conteúdo ocupa uma posição de prestígio como técnica de coleta de dados nas Ciências Sociais em geral, porém existem diferentes posturas sobre quais seriam suas formas, características e práticas em cada uma das disciplinas. Conforme proposto por Laurence Bardin (2011), a análise de conteúdo pode transformar documentos textuais em dados quantitativos e, formulando deduções lógicas por meio da análise qualitativa, explorar hipóteses, questões ou pressupostos, podendo ser aplicada a vários tipos de pesquisas. O presente artigo tem como objetivo explorar os alcances e as potencialidades de tal ferramenta ao apresentar duas pesquisas que aplicam estratégias de análise de conteúdo traçadas para estudar a política externa e o regionalismo, duas áreas comuns da ciência política e das relações internacionais para as quais a

\footnotetext{
Pesquisadora Doutora do Laboratório de Análise Política Mundial (Labmundo), Instituto de Estudos Sociais e Políticos da Universidade do Estado do Rio de Janeiro (IESP-UERJ), Rio de Janeiro, RJ, Brasil. E-mail: <daniellecsilva87@gmail.com>

2 Pesquisadora Doutora e professora colaboradora. Pós-doutoranda no Programa de Pós-graduação em Relações Internacionais, Instituto de Filosofia e Ciências Humanas, Universidade do Estado de Rio de Janeiro, Rio de Janeiro, RJ, Brasil. E-mail: <granjahernandezlorena@gmail.com>
} 
análise de conteúdo pode ser de extrema utilidade devido a sua mutabilidade e versatilidade na hora de desenhar uma pesquisa.

Consideramos que a análise de conteúdo, enquanto técnica metodológica, pode ser realizada de muitas formas, já que as estratégias elaboradas para analisar os conteúdos dependem não só do objeto de estudo, mas também das escolhas feitas pelo pesquisador/a e sua equipe. Nesse sentido, o/a pesquisador/a tem a capacidade de decisão sobre qual abordagem adotar ao traçar sua estratégia, sendo ela dependente da pesquisa (seus objetivos, perguntas, supostos e hipóteses). Existem diferentes caminhos a seguir para construir um desenho de análise de dados que possa ser replicado (em diferentes momentos e por distintas pessoas). Assim, haverá tantas técnicas de análise de conteúdo quantas pesquisas e pesquisadores, sendo isso relativo também ao contexto: diferentes momentos da análise, às modas e modismos praticados na/s respectiva/s disciplina/s e aos próprios conteúdos (no plural, já que se vem diversificando e multiplicando os formatos em que as fontes se disponibilizam).

Em primeiro lugar, objetiva-se apresentar uma discussão conceitual sobre quais seriam as vantagens e desvantagens da utilização das diferentes técnicas de análise de conteúdo. São apresentados um breve histórico da sua utilização no campo das Ciências Sociais, e seus fundamentos teórico-conceituais, para focar nos objetivos do método da análise de conteúdo a fim de identificar suas potencialidades analíticas. Na segunda parte do texto, a utilização da técnica da análise de conteúdo é exemplificada através de duas pesquisas que aplicaram estratégias seguindo os objetivos das pesquisas e as decisões das respectivas pesquisadoras, sendo essas as duas características que nos interessam ressaltar no presente artigo sobre a análise de conteúdo e suas potencialidades intrínsecas.

Existem distintas abordagens que tradicionalmente têm sido desenvolvidas por pesquisadores das ciências sociais, em cuja área encontramos escolas já clássicas que entenderam e desenvolveram certos tipos de análises de conteúdo. Tais escolas se diferenciam em algumas características ontológicas e epistemológicas. Porém, consideramos que a escolha de determinada técnica ou estratégia de 
pesquisa depende diretamente das decisões tomadas pelo pesquisador/a para construir seu desenho. Em termos mais gerais, tal escolha dependerá do objeto de pesquisa, das perguntas estruturadas pelo/a pesquisador/a e, sobretudo, da abordagem teórico-conceitual que esteja sendo argumentada nesse percurso. Por esse motivo, consideramos que a estratégia de análise de conteúdo é dependente diretamente do tipo de pesquisa e, em último caso, construída pelo/a pesquisador/a paulatinamente durante o transcurso desta. Portanto, a análise de conteúdo é relativa. Nesse sentido, pretendemos nos posicionar no debate sobre a validez das pesquisas. Há quem considere que, por ser uma técnica essencialmente construída por qualitativistas, seria uma forma de interpretação da realidade de menor alcance explicativo. Nossa posição é a defesa da análise de conteúdo como técnica desenhada para cada pesquisa, porém seguindo critérios lógicos e padrões de controle de nossas próprias interpretações.

Consideramos também que existem distintas “análises” possíveis para diferentes "conteúdos". Sendo dependentes do objeto da pesquisa, as análises são variadas, as escolhas de quais são os caminhos plausíveis e as estratégias para alcançar determinados resultados, insights ou elementos de análise também se multiplicam. Por sua vez, os veículos pelos quais os conteúdos estão sendo distribuídos e seus formatos possíveis também se tornaram múltiplos (não únicos).

Traçamos as técnicas de pesquisa de conteúdo a partir das experiências concretas de duas pesquisas na área da análise de política externa. Explicitando, justamente, as diferentes decisões tomadas em cada um dos momentos da construção da estratégia de pesquisa com o fim de evidenciar os argumentos da primeira parte: a dependência da estratégia ao tipo de pesquisa e às escolhas do pesquisador. Nesse transcurso, também se fazem evidentes as possíveis réplicas, os trade offs experimentados no momento de tomar cada decisão metodológica e, especialmente, a riqueza conceitual e analítica que tais técnicas de análise podem trazer para ilustrar argumentos, aumentando sua validez científica. Propomos explicitar o 
processo de construção do desenho da pesquisa, sua metodologia, para, entre outras coisas, dotá-la de transparência. Necessária em qualquer pesquisa que procure gerar conhecimento de qualidade, a transparência requer o acesso ao desenho da pesquisa, aos métodos e à orientação teórica adotada (SALMONA; KACZYNSKI, 2016).

Por fim, colocamos algumas reflexões sobre as infinitas possibilidades que as técnicas de análise de conteúdo trazem às pesquisas em análise de política externa, quando combinadas com tecnologias novas, boas e inovadoras práticas de pesquisa e criativas estratégias de análise.

\section{Trajetória da análise de conteúdo: inícios, escolas e novas ferramentas}

Tradicionalmente, entende-se que o surgimento da análise de conteúdo como procedimento analítico de comunicações jornalísticas ocorreu no início do século XX, nos Estados Unidos, tendo a Universidade de Columbia como pioneira dos estudos quantitativos de material de imprensa e propaganda durante a Primeira Guerra Mundial. Após cair em descrédito no período seguinte à Segunda Guerra Mundial, a análise de conteúdo volta ao meio acadêmico nos anos 1950, principalmente no campo da psicolinguística. Então, novas perspectivas metodológicas foram sendo desenvolvidas visando solucionar problemas que ainda não eram abrangidos pela análise de conteúdo, expandindo tais questionamentos para outras áreas das ciências sociais, como a linguística, a história, a sociologia e a ciência política, cada qual contribuindo de forma especial para o desenvolvimento dessa abordagem metodológica (CAPPELLE; MELO; GONÇALVES, 2003). O presente texto pretende se inscrever nesse caminho de desenvolvimento metodológico intra e transdisciplinar. Com tal intuito, propomos inserir a análise de política externa, subárea das relações internacionais no conjunto de campos 
de pesquisa que empregam a análise de conteúdo como estratégia válida e de sucesso nas pesquisas empiricamente orientadas. ${ }^{3}$

$\mathrm{Na}$ América Latina tem se difundido muito o livro de Bardin (2011), cuja tradução teve maior impacto na sociologia e na ciência política vernáculas. Porém, existem diferentes visões do que a análise de conteúdo é ou não é, e de como ela pode ser uma ferramenta de análise útil para as ciências sociais. Outro livro que também tem obtido difusão a partir de suas traduções para o espanhol e o português é o de Krippendorf (2004). Ambos são exemplos da multiplicidade de visões existentes por trás da técnica da análise de conteúdo. Enquanto Bardin (2011) classifica a ferramenta como uma técnica qualitativa, a abordagem de Krippendorf (2004) é pensada mais para análises quantitativas dos conteúdos (sobretudo textuais), visão em que a contagem das frequências dos tópicos identificados como categorias passa a ser central. Existem também outras visões que consideram a análise de conteúdo uma técnica mais interpretativa, que não pode ser dividida da sua intenção, da concepção do mundo e das simbologias que nele se representam - por exemplo, a visão do discurso foucaultiana (NEUENDORF, 2002).

$\mathrm{Na}$ academia americana também há certa confusão acerca das formas da análise de conteúdo em sua gênese. Apesar de generalizada a ideia de que essa metodologia foi incorporada a partir dos trabalhos de Harold Lasswell (1927) sobre a propaganda da Primeira Guerra Mundial, vale a pena ressaltar que o termo análise de conteúdo foi pela primeira vez colocado em inglês (content analysis) em 1941 por Waples e Berelson (apud KRIPPENDORFF, 2004, p. 3). Mais remotamente, podemos pensar nas leituras e interpretações dos livros sagrados da antiguidade, dos livros teológicos ou das pinturas e elementos rupestres como um tipo de análise de conteúdo; a sistematização, por sua vez, também foi utilizada pela Igreja Católica na época da Inquisição, e tais práticas nos dias atuais

3 A estratégia de análise de conteúdo vem sendo utilizada por pesquisas dentro da área (MARIANO, 2007; CAETANO, 2011; NETO, 2012; GRANATO, 2015; KFURI, 2015; LUSTIG, 2016). Nossa especial contribuição aqui é a atenção dada à construção metodológica e ao desenvolvimento de técnicas específicas de análise de conteúdo como elementos-chave na construção das evidências empíricas que sustentam argumentos cada vez mais densos e robustos. 
poderiam configurar verdadeiras bases de dados. Em seu sentido histórico, Krippendorf também atribui um papel primordial às discussões dos conteúdos filosófico-teológicos dos livros religiosos, enquanto identifica a primeira sistematização da "estrutura inerente a um conteúdo" nos trabalhos alemães do começo do século XX particularmente Eugen Löbl, em 1903, e Max Weber, em 1911 -, que foram pioneiros na análise sistemática simbólica da imprensa. Nesse quesito, o papel de Berelson e Lazarsfeld (The analysis of communication content, de 1948) também é primordial em sua análise da imprensa escrita do século XIX (KRIPPENDORFF, 2004, p. 5-10).

Mantendo a perspectiva histórica, podemos pensar que a trajetória das estratégias de análise de conteúdo também depende do tipo de conteúdo, dos veículos e formatos que ele adquire. Nesse sentido, entre a quantidade e velocidade de circulação da informação dos séculos passados e de nosso presente, pode-se traçar uma trajetória de constante crescimento com grandes saltos em momentos específicos (CASTELLS, 2000); hoje tais saltos são exponenciais e cada vez maiores. O volume, a velocidade e a variedade dos dados não estruturados que podem ser processados a partir da internet é inesgotável. Tais são as características do conceito de big data. Discute-se atualmente se outras duas categorias complementam o conceito: a veracidade e o valor. A quantidade incontrolável de dados criados por segundo no mundo dá à referência empírica as três primeiras características do big data, as outras duas foram decorrentes de seu uso pelos mais variados mercados (PATGIRI; AHMED, 2016).

O termo big data tem várias décadas de utilização, embora haja uma constante transformação de seus significados. Podemos nos remeter à década de 1940 para entender seu começo na realidade ontológica (DONTHA, 2017), porém o termo foi utilizado pela primeira vez em 1997 (COX; ELLSWORTH, 1997). Em sua acepção e conotação atuais, o termo big data foi introduzido em 2005 para se referir à impossibilidade de tratamento do volume e da variedade de dados com as técnicas tradicionais (O'REILLY, MOUGALAS, 2005). Existem vários posicionamentos nas discussões sobre o assunto, consequentes da complexidade do big data: 
Em uma definição simples, consideramos big data uma expressão que compreende diferentes conjuntos de dados muito amplos, altamente complexos, desestruturados, organizados, armazenados e processados utilizando métodos e técnicas específicas para processos de negócios (CHAORASIYA; SHRIVASTAVA, 2015, p. 1, tradução nossa). ${ }^{4}$

Tal complexidade se vê nas consequências que o uso indiscriminado de técnicas de mercado no tratamento desses dados tem trazido para nosso cotidiano. As restrições à igualdade e à liberdade de acesso à vida, assim como para a democracia e seu funcionamento são algumas delas e necessitam de maiores esforços de pesquisa. Cathy O'Neil (2016) chama os algoritmos desenvolvidos por empresas e agências públicas de armas de destruição matemática no livro homônimo no qual considera esse o lado escuro do big data. Ela analisa as utilizações de algoritmos para selecionar o acesso a sistemas e mercados sem o suficiente cuidado com as consequências em termos de justiça social e distributiva desses usos (O’NEIL, 2016). Talvez o exemplo mais paradigmático da importância pública do big data e de sua ingerência nos processos políticos seja a forma como se têm desenvolvido as campanhas eleitorais ao redor do mundo nos últimos anos.

A utilização de métodos matemáticos para tratar conteúdos textuais em dados não estruturados é comumente conhecida com o termo de text mining (mineração de textos), e sua principal característica é a desestruturação no tratamento que se faz deles, devido ao volume.

A quantidade crescente de dados textuais disponíveis em diferentes aplicativos criou a necessidade de avanços no design algorítmico, que podem aprender padrões interessantes a partir dos dados de maneira dinâmica e escalável. Embora

4 No original: "In a simpler definition we consider big data to be an expression that comprises different data sets of very large, highly complex, unstructured, organized, stored and processed using specific methods and techniques used for business processes." 
os dados estruturados sejam geralmente gerenciados com um sistema de banco de dados, os dados de texto geralmente são gerenciados por meio de um mecanismo de pesquisa devido à sua desestruturação. (AGGARWAL; ZHAI, 2012, p. 2 , tradução nossa). ${ }^{5}$

Técnicas como a de vetorizar os textos e a stemização das palavras para serem passíveis de tratamento quantitativo - visto que, por seu volume, não poderiam ser tratadas de outra forma -, inscrevem-se dentro das técnicas de análises de conteúdo, embora a ideia seja a desestruturação dos textos para poder entendê-los. Na modelagem de tópicos, por exemplo, é possível contabilizar as palavras usadas por quanto elas se distanciam de outras (nos vetores) e não necessariamente em função de seu significado. Inclusive, nos modelos temáticos realizados por machine learning, nas análises de imagens das redes sociais e no profiling, os textos têm cada vez mais conteúdo quantitativo, se tratados na lógica de big data. ${ }^{6}$

Essa miscelânea de análises de conteúdo que, em grande medida, dependem do enfoque teórico proposto, dos objetivos da pesquisa e das diferentes técnicas usadas, transformam-se em múltiplas vantagens em termos de resultados de pesquisa e evidência empírica

5 No original:" The increasing amounts of text data available from different applications has created a need for advances in algorithmic design which can learn interesting patterns from the data in a dynamic and scalable way. While structured data is generally managed with a database system, text data is typically managed via a search engine due to the lack of structures."

6 Os termos vetorizar e stemizar se referem à preparação prévia necessária para analisar qualquer texto como big data, sua desestruturação. As palavras, que juntas adquirem significado em orações, são transformadas em vetores de palavras para conseguir tratá-las como dados quantitativos em termos de frequência e espaço; o vetor das palavras que têm mais frequência em determinado corpus pode, por exemplo, ser modelado espacial (por distância entre elas) e tematicamente (por significado de cada palavra, atribuído na codificação). Já o ato de stemizar é como comumente é chamada a redução de uma palavra a sua raiz etimológica principal para, assim, contabilizá-la somente de uma forma e não em todas suas possíveis derivações a partir de gerúndios, conjugações ou advérbios. Ambas as operações preparam um texto qualquer desestruturando seu conteúdo em um conjunto de palavras para ser tratadas como dados quantitativos. Já no profiling, a mesma lógica é aplicada à análise de imagens e conteúdo das redes sociais; analisam-se vários perfis públicos no intuito de gerar informações úteis para pesquisas de mercado, opinião pública e inclusive emprego. A técnica de machine learning é uma automatização feita a partir de comandos de base, sendo geralmente usada para codificar e modelar; o software (ou o algoritmo de uma linguagem como Python ou R) consegue entender as primeiras codificações feitas manualmente e, posteriormente, as aplica automaticamente. 
para sustentar argumentos. Tal heterogeneidade de visões é uma das posturas que podemos considerar mais apropriada para pensar nas estratégias de pesquisa de análise de conteúdo em particular e, mais amplamente, nos alcances dessa ferramenta para as pesquisas em diversos campos da ciência política e das relações internacionais. Advogamos pela necessidade crescente de sua utilização em pesquisas que gerem conhecimento para entender os processos que afetam diretamente os objetos de estudo.

Nossa abordagem traz como elementos inovadores: $i$ ) a aceitação tácita da heterogeneidade teórico-epistêmica para tratar a técnica de análise de conteúdo, argumento que, sem chegar a explicitá-lo dessa forma, já fora esboçado por Rocha e Carlomagno (2016); e ii) a proposta e exemplificação de estratégias de análise de conteúdo aplicadas a pesquisas inéditas na análise de política externa.

A análise de conteúdo com a qual trabalhamos tem por princípio uma abordagem investigativa que segue o modelo proposto por Bardin (2011). A autora a concebe como "um conjunto de técnicas de análise das comunicações visando obter, por procedimentos sistemáticos e objetivos de descrição do conteúdo das mensagens, indicadores (quantitativos ou não) que permitam a inferência de conhecimentos relativos às condições de produção/recepção dessas mensagens" (2011, p. 48). Desse modo, abrange tanto o rigor da objetividade científica quanto a fecundidade da subjetividade do pesquisador, além de não negligenciar as influências socioespaciais e o contexto no qual o material textual está inserido. Tendo uma função heurística, o método consiste numa tentativa exploratória de verificação de hipóteses, questões ou pressupostos, e também de análise sistemática para sua confirmação ou refutação.

A intenção da análise é transformar o conteúdo de variados materiais textuais em dados quantitativos e analisá-los de forma qualitativa, realizando deduções lógicas. A quantificação dos elementos textuais, feita na primeira etapa da pesquisa, serve para a organização dos dados, voltando-se, por exemplo, para a frequência com que surgem determinados elementos nas comunicações e produzindo uma codificação do material que permite ao pesquisador "apreender 
a visão social de mundo por parte dos sujeitos, autores do material textual em análise" (CAPELLE; MELO; GONÇALVES, 2003). Por sua vez, os enfoques qualitativos dessa análise concentram-se na presença ou ausência de características no material analisado, produzindo então interpretações mais complexas com base na inferência (BARDIN, 2011; MINAYO, 2000 apud CAPPELLE; MELO; GONÇALVES, 2003, p. 5). Somado à abordagem quantitativa e qualitativa, o uso de programas de computador para a codificação de textos para testar hipóteses e obter percepções novas corrobora aquilo que uma análise tão somente qualitativa não conseguiria produzir (VILELA; NEIVA, 2011; SANTOS; OLIVEIRA, 2015) 7 .

Essa perspectiva analítica quantitativa e qualitativa possibilita ao/à pesquisador/a não apenas material empírico para sustentar argumentos causais, explicativos ou descritivos analiticamente densos, mas também permite identificar frequências, ocorrências e co-ocorrências de tópicos/categorias, além de conhecer os elementos que são incluídos ou deixados de lado no processo de formulação da política externa, nos exemplos aqui apresentados. Tal metodologia permite uma quantificação e sistematização do conteúdo de materiais discursivos de atores encarregados da prática da política externa (presidentes e ministros, por exemplo) e também de documentos políticos que registram planos e/ou ações políticas dos múltiplos agentes atuantes na esfera internacional. Dessa forma é possível perceber que a política externa de um país é resultado da heterogeneidade discursiva de sua sociedade, gerando a identidade coletiva do Estado, que opera em uma estrutura sistêmica e doméstica, sofrendo mudanças, revelando processos e provocando novas leituras de seus objetivos.

Ressalta-se que a preocupação da metodologia aqui trabalhada não é com a semântica ou com os diversos significados ocultos, inconscientes, sociais ou ideológicos presentes nos materiais

7 Nesse sentido, a utilização de diferentes softwares de análise vem proliferando exponencialmente. Alguns textos que pretendem sistematizar o uso de tais ferramentas já ficaram obsoletos nos dados, embora consigam traçar cabalmente a trajetória e a rapidez do desenvolvimento de tais tecnologias (REVUELTA-DOMÍNGUEZ; SÁNCHEZ-GÓMEZ, 2005; LUCAS et al., 2015; SALMONA; KACZYNSKI, 2016; ZHAO et al., 2016). 
textuais, o que é considerado análise de conteúdo sob outra perspectiva teórico-analítica. Também não é nossa intenção observar processos ou mecanismos de constituição de sentidos e de sujeitos, como é feito pela escola de análise de discurso e aplicado por autores como Foucault, Pêcheux e Fairclough, ou pela teoria pós-estruturalista das relações internacionais. Nossa finalidade é utilizar a análise de conteúdo para realizar o levantamento das informações, propriedades e peculiaridades presentes em nossos respectivos corpus analíticos - materiais que ainda estão academicamente inexplorados e que são estimados por qualquer pesquisa no campo da análise da política externa. Tal levantamento ainda é de caráter qualitativo, independentemente das maneiras como os dados extraídos possam ser tratados posteriormente, ou mesmo apresentados, já que se trabalha com os produtos dos textos, buscando compreendê-los por meio de seu conteúdo a partir da subjetividade do/da próprio/a pesquisador/a. Portanto, o desígnio máximo de nosso uso da análise de conteúdo é revelar as intenções e diretrizes políticas, bem como suas possíveis relações com os contextos históricos e conjunturais do recorte analítico pesquisado, seguindo alguns critérios básicos que dependeram da escolha do objeto, do recorte temporal e do marco teórico-analítico, entre outros fatores.

Conforme assinalado por Bardin (2011, p. 36), existem diversas formas de se fazer uma análise de conteúdo, adequando-a à pesquisa que está sendo realizada, principalmente ao tema e ao objeto, podendo, ainda, depender do tipo de elemento comunicacional analisado e do tipo de interpretação que o/a pesquisador/a objetiva. A autora propunha três fases para a realização de uma análise de conteúdo: $i$ ) a pré-análise, que corresponde à organização do material, como a escolha dos documentos e do objetivo; ii) a exploração do material, com a classificação e codificação das fontes; e iii) o tratamento dos resultados, por meio da inferência (dedução lógica) e interpretação dos dados. A inferência em si consiste numa fase intermediária entre a descrição analítica - que funciona segundo procedimentos sistemáticos e descritivos do conteúdo das mensagens - e a interpretação conclusiva do pesquisador. 
As estratégias mais utilizadas dentro da análise de conteúdo são a análise temática e a categorização. Segundo Chizzotti (2013), a análise de conteúdo visa decompor as temáticas de um texto, codificadas em algumas categorias de modo a permitir a enumeração das unidades e as inferências delas realizadas, que podem ser visíveis ou não. É através da categorização, ${ }^{8}$ ou seja, da classificação de elementos constitutivos de um conjunto seguindo critérios previamente definidos, que é possível extrair os significados temáticos, a frequência da citação de alguns temas e/ou palavras, e uma infinidade de possibilidades que também dependem da criatividade e curiosidade do pesquisador.

Destaca-se a grande importância da etapa de codificação, inserida na fase de exploração do material, pois a codificação é "o processo pelo qual os dados brutos são transformados sistematicamente e agregados em unidades, as quais permitem uma descrição exata das características pertinentes do conteúdo" (HOLSTI, 1969 apud BARDIN, 2011, p. 133). É nela que são feitos os recortes em unidades de registro ${ }^{9}$ e de contexto, ${ }^{10}$ sendo os requisitos para uma boa categorização a exclusão mútua, homogeneidade, pertinência, objetividade, fidelidade e produtividade. Na fase exploratória do material, busca-se reduzir dados para conseguir mais informações a partir das fases subsequentes. Tal como assinalado por Revuelta-Domínguez e Sánchez-Gómez (2005), a informação é "simplificada e selecionada a fim de que seja mais maleável. As tarefas de redução de dados constituem procedimentos racionais que habitualmente

8 Segundo Bardin, "as categorias são rubricas ou classes, as quais reúnem um grupo de elementos (unidades de registro) sob um título genérico, agrupamento esse efetuado em razão das características comuns destes elementos" (2011, p. 147). Resumindo, a análise categorial é a forma pela qual se realizam classificações e recenseamento do conteúdo por meio da criação de categorias (similares a gavetas de classificação de arquivos, em que se vai colocando o conteúdo textual dentro de diferentes espaços - categorias de análise).

9 Unidade de registro é a unidade de significação codificada e corresponde ao segmento de conteúdo considerado unidade de base visando à categorização e à contagem de frequências, podendo ser de natureza e dimensões muito variáveis (BARDIN, 2011, p.134).

10 Unidade de contexto serve de compreensão para codificar a unidade de registro e corresponde ao segmento da mensagem, cujas dimensões (superiores às da unidade de registro) são ótimas para a compreensão da significação exata da unidade de registro, podendo ser, por exemplo, a frase para a palavra ou o parágrafo para o tema (BARDIN, 2011, p. 137). 
consistem na categorização e codificação; identificando e diferenciando unidades de significado" (2005, p. 2, tradução nossa).

Assim, a codificação consiste na atribuição manual de um código (marca ou categoria) a um fragmento de informação (unidade de análise, ou de registro) extraída das fontes (documentos); para isso, pode-se estabelecer critérios sistematizados de designação de categorias ou simplesmente realizar operações mecânicas. De fato, às vezes, a criação das categorias e seu conteúdo (codificação) são construídas ao mesmo tempo (in vivo), ou seja, durante a realização da análise, por meio da observação dos dados e insights do pesquisador; outras, têm padrões de categorização estabelecidos previamente à análise, definindo o escopo do que será investigado no material. $\mathrm{O}$ primeiro é um procedimento indutivo, conforme se examinam os dados, criam-se as categorias e se lhes confere os fragmentos de informação (codificando); o segundo, por sua vez, é um processo dedutivo, já que se preestabelece teoricamente uma associação entre a informação e as categorias previamente delimitadas.

Para codificar é necessário definir o elemento básico de análise em que aparece o termo procurado, podendo ser uma palavra (ou um conjunto delas), frase ou locução, entre outros, que serão as unidades de registro. $\mathrm{O}$ quadro abaixo exemplifica a aplicação do modelo de pesquisa de Bardin a partir de um trecho do discurso de Dilma Rousseff.

Quadro 1 - Exemplo aplicado do modelo proposto por Bardin

\begin{tabular}{|c|c|c|c|c|}
\hline Tema & Categorias & Subcategorias & Unidades de registro & Unidade de contexto \\
\hline $\begin{array}{l}\text { Direitos } \\
\text { Humanos }\end{array}$ & $\begin{array}{c}\text { Autodeterminação } \\
\text { dos povos }\end{array}$ & $\begin{array}{l}\text { Colonialismo; } \\
\text { Conflito; } \\
\text { Haiti; } \\
\text { Israel; } \\
\text { Malvinas; } \\
\text { Novas naçõ̂es; } \\
\text { Palestina; } \\
\text { Respeito à soberania e } \\
\text { à autodeterminação. }\end{array}$ & $\begin{array}{c}\text { Soberania; } \\
\text { Autodeterminação; } \\
\text { Desenvolvimento } \\
\text { soberano; } \\
\text { Estado palestino; } \\
\text { Conflito Israel-palestina. }\end{array}$ & $\begin{array}{l}\text { Exemplo: (Dilma, 2011) “0 reconhecimento ao } \\
\text { direito legítimo do povo palestino à soberania e } \\
\text { à autodeterminação amplia as possibilidades de } \\
\text { uma paz duradoura no Oriente Médio. Apenas } \\
\text { uma Palestina livre e soberana poderá atender } \\
\text { aos legítimos anseios de Israel por paz com } \\
\text { seus vizinhos, segurança em suas fronteiras e } \\
\text { estabilidade política em seu entorno regional." }\end{array}$ \\
\hline
\end{tabular}

Fonte: adaptado de Silva (2016). 
O primeiro passo consiste na identificação do material textual (no caso, pronunciamentos oficiais) que contém o conteúdo relativo aos direitos humanos, que foi realizada por meio da busca por palavras que identificam a temática (como "direitos humanos", "direitos fundamentais"). O segundo passo consiste na definição da categoria: no exemplo, "autodeterminação dos povos" foi elaborada de forma dedutiva, por se tratar de um assunto político frequente dentro do campo dos direitos humanos; já as subcategorias foram sendo criadas de forma intuitiva a partir do que aparecia na leitura do material textual (quais países ou conflitos eram mencionados). $\mathrm{O}$ aparecimento intuitivo das subcategorias está relacionado à unidade de registro por causa das palavras específicas encontradas durante a leitura do material e que identificam o conteúdo a ser codificado dentro da categoria. Por fim, a unidade de contexto é o trecho (parágrafo) do material textual, no exemplo de um pronunciamento realizado por Dilma Rousseff que aborda o assunto em questão e que foi codificado dentro da referida categoria e em subcategorias correspondentes ("Israel", "Palestina", "respeito à soberania e à autodeterminação").

Até aqui, pretendeu-se dar um panorama geral das múltiplas possibilidades que existem na análise de conteúdo como ferramenta e como estratégia. A disponibilidade dos dados, a pertinência deles e as possibilidades de acesso a formas de tratamento cada vez mais sofisticadas são condicionantes que todos os pesquisadores enfrentam durante o desenho da pesquisa desde as etapas iniciais do processo de reflexão. A seguir, consideramos mais de perto os desenhos implementados para conseguir ilustrar tais escolhas.

\section{Exemplos de pesquisas aplicadas à política externa}

Neste tópico, pretendemos ilustrar os postulados da primeira parte do artigo a partir da breve descrição de duas pesquisas que utilizaram a análise de conteúdo como técnica fundamental para a obtenção de resultados, contraste de hipóteses e supostos, 
assim como para realizar formulações conceituais argumentativas genuínas. $^{11}$

Ambas as pesquisas aqui expostas compartilham a argumentação do artigo de que a maneira de fazer análise de conteúdo depende diretamente do tipo e dos objetivos de pesquisa, bem como das escolhas do/a pesquisador/a. As pesquisas se apoiaram em seus próprios supostos e hipóteses para poder desenhar a estratégia que iria ilustrar os argumentos afirmados em cada pesquisa, e conseguiram com êxito alcançar os resultados esperados. Mas tal estratégia analítica não é um caminho fácil, de fato existem distintos trade offs em cada passo avançado durante a análise. Uma breve exploração de ambos os exemplos ilustrará este ponto, a fim de entendermos quais são as limitações e implicações da escolha de diferentes estratégias da análise de conteúdo, além de fornecer resultados interessantes no campo da política externa.

Em primeiro lugar, explicitam-se as principais diretrizes metodológicas utilizadas na pesquisa a respeito da política externa brasileira no campo dos direitos humanos e, principalmente, os resultados da análise do primeiro governo de Dilma Rousseff. ${ }^{12} \mathrm{Em}$ segundo, são abordadas as principais características da estratégia

11 A justificativa da escolha obedece ao critério de que, ao serem nossas próprias pesquisas de doutoramento, conhecemos todo o processo de construção da estratégia e o desenho de pesquisa de perto, assim como suas limitações. Cabe ressaltar que ultimamente existem pesquisas que utilizam a análise de conteúdo para objetos das relações internacionais e se preocupam com a explicitação da construção da estratégia metodológica, caso do trabalho de Carola Lustig (2016), que analisa o posicionamento brasileiro perante seus vizinhos da América do Sul por meio do conteúdo das comunicações oficiais do Itamaraty. A pesquisa da autora se baseia numa orientação teórica definida e procura identificar em tais comunicados elementos discursivos que permitam considerar o posicionamento brasileiro como hard ou soft power.

12 A presente análise é oriunda da pesquisa realizada para tese de doutorado em ciência política que explanou a respeito da percepção sobre os direitos humanos dos governos do período pós-redemocratização do Brasil (de 1986 a 2014), identificando os tópicos considerados mais relevantes para cada governo, suas contribuições para o desenvolvimento de uma posição ativa do Estado brasileiro em relação aos direitos humanos na política externa e a proximidade entre a política doméstica e a política externa brasileira nesse tema. Metodologicamente, os resultados da análise de conteúdo de pronunciamentos oficiais dos presidentes auxiliaram a compreensão do posicionamento de cada um dos governos em relação aos direitos humanos, verificando diferenças e/ou similaridades, os tópicos sobre direitos humanos abordados e os resultados das posições dos presidentes para a política externa e, principalmente, para a análise da inter-relação entre a política doméstica e a política externa (SILVA, 2016). 
de pesquisa desenhada para construir o processo de tomada de decisões do Mercosul entre os anos 1991-2017. ${ }^{13}$

\section{Análise da política externa brasileira de direitos humanos durante o governo Dilma Rousseff (2011-2014)}

Partindo da ideia teoricamente fundamentada em Milner (1997) de que o processo de elaboração da política externa brasileira de direitos humanos se modificaria com a natureza dos problemas contextuais e os impactos pretendidos por cada governo, produziu-se, por meio dos resultados da análise de conteúdo de pronunciamentos oficiais do primeiro governo da presidenta Dilma Rousseff (2011-2014), uma compreensão analítica diferenciada sobre a política externa brasileira de direitos humanos. A pesquisa aplica a análise de conteúdo aos pronunciamentos presidenciais, identificando a percepção sobre os direitos humanos do governo Rousseff e verificando os principais temas de agenda e seu grau de inter-relação entre os níveis doméstico e externo. ${ }^{14}$

\section{A construção da pesquisa}

Sendo a fala discursiva socialmente construída, moldada pelos processos da prática social, o conteúdo de pronunciamento oficiais pode ser utilizado como ferramenta de análise sobre como as mudanças nos objetivos dos governos (HERMANN, 1990) impactam na política externa de direitos humanos e, principalmente, sobre as ideias que geram o escopo interpretativo para as ações dos atores encarregados da tomada de decisão (chefes de Estado e de governo), desvelando as "crenças com princípios" (KEOHANE;

13 A pesquisa iniciou-se durante a tese de doutorado (quando foram levantadas as informações até 2014) e posteriormente foi desenvolvida no pós-doutorado (atualmente o projeto continua em andamento). O principal argumento defendido nela é que tanto a construção institucional feita durante o processo, quanto os padrões assimétricos desenhados nas negociações e os diferentes ciclos de convergência/divergência ideológica entre os governos são elementos que podem explicar o desenvolvimento e a trajetória do Mercosul (GRANJA HERNÁNDEZ, 2016a).

14 Fundamentado na ideia de que o nível de inter-relação contextual demonstraria a expressão do conflito doméstico no nível externo, e vice-versa, pressupõe-se que, quanto maior a interação entre os níveis doméstico e externo, maior será a convergência entre as ideias e os interesses da agenda da política doméstica de direitos humanos e da política externa de direitos humanos, ocorrendo, assim, sua politização. 
GOLDSTEIN, 1993) de suas concepções dos direitos humanos. Partindo então desse aporte teórico que considera as ideias como exercendo um papel importante na formulação da política externa, a análise de conteúdo foca na identificação dos interesses desses atores, procedendo-se à investigação a partir dos pronunciamentos oficiais da Presidência da República do Brasil.

Os pronunciamentos oficiais, fontes primárias da pesquisa, encontram-se disponibilizados no site da Biblioteca da Presidência da República ${ }^{15}$ e no site da Presidência da República, ${ }^{16}$ além de estarem organizados no banco de discursos do Laboratório de Análise Política Mundial (Labmundo). Utilizando o software NVivo $10,{ }^{17}$ uma triagem foi realizada por meio da ferramenta de busca por palavras para identificar os pronunciamentos que continham menção ao termo "direitos humanos". Para abranger o maior número possível de pronunciamentos com menções ao tema, a triagem considerou não somente a locução "direitos humanos", como também palavras ou locuções ${ }^{18}$ homólogas, como "direitos fundamentais", "dignidade humana" e "direitos dos cidadãos", entre outras.

A partir da triagem, prosseguiu-se a leitura dos pronunciamentos selecionados identificando os trechos que continham uma posição afirmativa ou sentença específica sobre o tema de direitos humanos (conforme explicado no Quadro 1). A seleção de tais trechos considerou os parágrafos em que se encontravam menções aos tópicos relacionados aos direitos humanos (material a ser codificado, ou seja, quantificado). Tais menções vão além da simples presença do termo "direitos humanos", tendo sido também considerados ao longo da codificação outros termos-chave, além de termos correlacionados às questões associadas ao amplo sentido do conceito de

15 Disponível em: http://www.biblioteca.presidencia.gov.br/pagina-inicial-3.

16 Disponível em: http://www2.planalto.gov.br/acompanhe-o-planalto/discursos\#b_start=0.

17 Segundo as informações do site, o NVivo é um software que suporta métodos qualitativos e variados de pesquisa, capaz de organizar, analisar e encontrar informações em dados não estruturados ou qualitativos, tais como entrevistas, respostas abertas de pesquisa, artigos, mídia social e conteúdo web. Disponível em: http://www.qsrinternational.com/nvivo-portuguese. Acesso em: 7 fev. 2020.

18 A ferramenta de busca por palavras do NVivo permite que locuções ou conjunto de palavras sejam buscadas dentro do material analisado. 
"direito humano" (direito das mulheres, igualdade racial, acesso à saúde e à educação, entre outros). Tais termos-chave serviram de base para a criação das categorias e (quando necessário) subcategorias temáticas, cujas presenças são consideradas representantes da concepção de quem discursa sobre o tema abordado. De acordo com a temática de seu conteúdo, os trechos textuais analisados foram agregados em suas referidas categorias, sendo que algumas referências textuais podem ser inseridas em mais de uma categoria por abordarem mais de uma temática.

Em seguida, foi realizada uma análise categorial desse conteúdo selecionado objetivando verificar quais foram os tópicos dentro do campo dos direitos humanos e a frequência de aparição de tais categorias nos pronunciamentos oficiais dos governos. Devido à extensão da pesquisa, optou-se por realizar uma seleção das dez categorias com maior quantidade de codificações para elaborar a explanação da perspectiva sobre os direitos humanos. Com isso, foi produzido material gráfico ${ }^{19}$ que demonstra a quantificação de tais elementos categoriais, produzindo evidência empírica para a construção analítica da política externa de direitos humanos do período analisado. Tal categorização realizada pelo software possibilita a construção de tabelas (que podem ser exportadas para o formato Excel) que apresentam a quantificação das categorias. A essa quantificação, soma-se a capacidade do NVivo de armazenar em um mesmo local todas as referências textuais de cada uma das categorias, possibilitando, assim, a análise qualitativa do material de acordo com seu contexto histórico, político e social.

Objetivando avaliar o grau da inter-relação entre os níveis doméstico e externo dos temas identificados, também foi feita uma classificação entre os pronunciamentos realizados em contexto doméstico ou contexto externo: aqueles proferidos no Brasil, que abordam questões de políticas domésticas ou à sociedade brasileira

19 Agradecemos a colaboração de Magno Klein Silva, doutor em ciência política do Instituto de Estudos Sociais e Políticos (IESP) da Universidade do Estado do Rio de Janeiro (UERJ), pesquisador do Labmundo e professor adjunto da Universidade da Integração Internacional da Lusofonia AfroBrasileira (Unilab), na elaboração do gráfico. 
foram categorizados como sendo de contexto doméstico, enquanto aqueles que foram proferidos fora do país, em eventos internacionais, ou referentes às questões internacionais, como a relação com outros países ou instituições internacionais, foram codificados como sendo de contexto externo. A predominância contextual de cada categoria analisada foi então definida por meio do cruzamento das codificações pertencentes a cada categoria temática com a referida categorização contextual dos pronunciamentos, ${ }^{20}$ ocorrendo também de um pronunciamento pertencer a ambos os contextos, como nos casos de recepções a chefes de Estado ocorridas no Brasil e de pronunciamentos em cerimônias de formatura de diplomatas.

Por meio da análise dos padrões de inter-relação (ou interação) entre os contextos doméstico e externo, verificou-se, quantitativa e qualitativamente, quais categorias sobre direitos humanos foram abordadas e em quais dos níveis contextuais ocorreu predominância da sua abordagem, demonstrando o grau de relevância (maior, menor ou similar) da categoria referente em cada um dos contextos. Fundamentado na ideia de que o nível de inter-relação contextual demonstraria a expressão do conflito doméstico no nível externo, e vice-versa, pressupõe-se que, quanto maior a interação entre os níveis doméstico e externo, maior seria a convergência entre as ideias e os interesses da agenda da política doméstica de direitos humanos e a da política externa de direitos humanos, portanto, maior seria sua politização. Com isso, a análise de conteúdo contribuiu para demonstrar empiricamente o fundamento teórico de Milner (1997) de que os contextos (doméstico ou externo) dos problemas abordados impactam, sim, no posicionamento do governo e nas medidas por ele tomadas.

A partir da identificação do contexto no qual o pronunciamento foi enunciado, a avaliação da inter-relação contextual foi realizada seguindo um ou mais fatores, entre eles: $i$ ) valor do percentual de cada contexto em relação à totalidade das codificações da categoria

20 Tal cruzamento das codificações foi feito graças à ferramenta do Nvivo, que permite o cruzamento entre os "nós", termo do software para designar as categorias criadas. 
(equivalente a $100 \%$ ) e a diferença entre eles, havendo predomínio de um dos contextos quando a diferença entre eles foi igual ou maior que $20 \%$; ii) a comparação entre os valores numéricos absolutos das codificações, havendo inter-relação quando a diferença for inferior a dez codificações; iii) a quantidade de codificações em dualidade contextual, ou seja, quando o pronunciamento pertence a ambos os contextos, havendo inter-relação quando identificada uma quantidade significativa de pronunciamentos nessa situação. Tais critérios de codificação e interpretação representam cabalmente as escolhas feitas pela pesquisadora referidas na primeira parte do texto.

\section{A política externa de direitos humanos do primeiro governo Dilma Rousseff (2011 - 2014)}

O primeiro mandato do governo Dilma caracterizou-se por certa prioridade em relação aos direitos humanos na política externa, evidenciada pelo voto a favor do envio de um inspetor da Organização das Nações Unidas (ONU) para investigar possíveis violações de direitos humanos no Irã, em maio de 2011, na condenação ao apedrejamento da iraniana Sakineh Ashtiani, e uma crítica à seletividade dos casos considerados violação aos direitos humanos, com a posição brasileira sendo contrária a todas as violações e abusos, que deveriam ser tratados de forma equânime (PATRIOTA, 2011). ${ }^{21}$

As 124 codificações da categoria "respeito aos direitos humanos" registram a ideia de Dilma sobre a responsabilidade do Estado na proteção aos direitos humanos, ao se posicionar arduamente contra violações e a continuidade da valorização da dimensão social dos direitos humanos para o desenvolvimento do país, que também se refletiu na política externa brasileira. O posicionamento do governo Dilma a respeito da subordinação do Estado aos direitos humanos está fundamentado em seu dever de protegê-los e não os violar (ROUSSEFF, 2011c), ressaltando as responsabilidades do Estado

21 Dilma deu prosseguimento à posição revisionista iniciada pelo governo Lula, criticando os double standards no tratamento e fiscalização dos direitos humanos pelas instituições internacionais, vide o voto brasileiro no Conselho de Direitos Humanos, em 2014, a favor do envio de uma comissão de inquérito para investigar violações cometidas por Israel durante confronto militar em territórios palestinos. 
brasileiro por violações ocorridas durante o Regime Militar, algo que pode ser diretamente ligado à identificação pessoal da presidenta com a questão. Destaca-se também a posição assumida no exercício dos direitos humanos em prol da melhoria de vida dos cidadãos, da igualdade social e da distribuição de renda, com a defesa de políticas sociais como significativo instrumento promotor dos direitos humanos. Dilma evocou, assim como o governo anterior (Lula 2003-2010), a dimensão social da democracia, ao promover a justiça social, a redução das desigualdades, valorizando as diferenças e combatendo a discriminação de gênero, raça, condição física, orientação sexual e diferenças de pensamento ou religião (ROUSSEFF, 2011d).

Considerando as afirmações de Dilma sobre a política externa do Brasil, ela apoiou os valores clássicos de defesa dos direitos humanos, de garantia das liberdades, de defesa da dignidade humana e de condenação do uso da violência, dando continuidade à tradição da diplomacia brasileira nesse campo. Somada à iniciativa do primeiro governo Dilma de colocar a defesa dos direitos humanos no centro da política externa (ROUSSEFF, 2011a), observa-se sua contínua defesa dos direitos humanos sem discriminação ou seletividade em nível internacional e nas instituições multilaterais, buscando evitar o que a presidenta chamou de uso dos direitos humanos como arma de luta política (ROUSSEFF, 2012d; 2014), ou seja, o uso político de questões relativas aos direitos humanos em prol de interesses políticos de alguns países. Exemplos da aplicação desse conceito foram observados nos casos do conflito na Síria, com o uso da violência contra civis, no trato do conflito Israel-Palestina e na questão da Ucrânia, ${ }^{22}$ nos quais o posicionamento da presidenta foi favorável ao cessar de hostilidades, à defesa do diálogo em prol do fim dos dramas humanitários causados pelos conflitos e à abstenção nas

22 O conflito na Ucrânia, iniciado no fim de 2013, foi inicialmente causado pela decisão do então presidente Viktor Yanukovich de romper o acordo de livre comércio com a União Europeia e de se alinhar com a Rússia, resultando em oposição do povo ucraniano, que sofreu forte repressão policial, ocasionando mortes. Mesmo após a destituição do presidente, o conflito se manteve principalmente na região da Crimeia, onde separatistas pró-Rússia (país contrário ao novo governo e que enviou militares para essa região) entraram em conflito com forças militares do governo ucraniano. 
votações no Conselho de Direitos Humanos $(\mathrm{CDH})$ de resoluções contra a Síria.

Além de manter a posição do Brasil na busca por soluções pacíficas e no respeito aos direitos humanos em situações conflitivas, Dilma apresentou ao sistema internacional o conceito de responsabilidade ao proteger (em inglês, responsibility while protecting - RwP), que complementaria a noção de responsabilidade de proteger ${ }^{23}$ (em inglês, responsibility to protect - R2P). A proposta buscava garantir que ações internacionais de proteção a civis não resultem em situações ainda piores de conflito e também pela prevenção do uso da força, que deveria respeitar limites e ser usada somente em último caso, tendo meios de accountability como o monitoramento das ações pela ONU. ${ }^{24}$

Fatores externos oriundos do contexto político internacional também impactaram a política externa de direitos humanos no governo Dilma, em particular o caso de espionagem de comunicações e interceptação de informações pessoais de cidadãos e de funcionários do governo brasileiro pela Agência de Segurança Nacional dos Estados Unidos (NSA), revelado por Edward Snowden, ${ }^{25}$ que provocou reações do governo Dilma em âmbito externo e doméstico. Ao discursar na tribuna da Assembleia Geral da ONU em 2013 e 2014, Dilma denunciou não só o desrespeito à soberania nacional do Brasil, mas a violação dos direitos humanos e civis fundamentais dos cidadãos do Brasil sob a alegação da tentativa de garantir o direito à segurança dos cidadãos norte-americanos. Centrada em questões de direitos civis, econômicos e sociais, tal situação introduziu um novo assunto de direitos humanos na atuação da política

23 Responsabilidade de proteger consiste na norma, adotada pela Cúpula Mundial das Nações Unidas em 2005, de que a comunidade internacional é incumbida de agir ou intervir quando um Estado falha na tarefa de proteger sua população, como genocídio, crimes de guerra, limpeza étnica e crimes contra a humanidade, sendo o uso da força o último recurso, apesar de ser o mais visado pelas potências.

24 Contudo, tal item acabou saindo da agenda da política externa de Dilma, não ocorrendo mais menções a ele após o ano de 2012.

25 Ex-analista de sistemas do Serviço de Inteligência Americano (Central Intelligence Agency - CIA) e ex-funcionário do NSA que tornou públicas informações sigilosas do serviço de inteligência dos Estados Unidos. 
externa brasileira: a questão do direito à privacidade do indivíduo, tendo como campo de atuação a internet (ROUSSEFF, 2013b).

De forma geral, há um equilíbrio na perspectiva sobre os direitos humanos do governo Dilma entre os direitos de primeira e segunda geração. A questão dos direitos civis é apreciada na obrigação do Estado de garantir a proteção aos direitos básicos dos cidadãos, estando vinculada à consolidação democrática do Estado brasileiro, e também na proteção à privacidade dos cidadãos, conforme levantado pelo caso da espionagem norte-americana. A isso, soma-se a preocupação com a dimensão social dos direitos humanos, exemplificada pelo combate à fome e à pobreza, pela promoção da igualdade social e pelas políticas de distribuição de renda, compartilhando a perspectiva social dos direitos humanos de Lula (SILVA, 2016).

Aprofundando as interpretações sobre a perspectiva e a atuação de Dilma na política externa de direitos humanos, faz-se necessário identificar, como apresentado no gráfico 1, os tópicos e as posições desse governo nesse campo, tanto em âmbito interno quanto no externo, e posteriormente, analisá-los qualitativamente.

Gráfico 1. Direitos Humanos nos pronunciamentos de Dilma Rousseff (2011-2014):

Categorias do pronunciamento oficial e sua predominância contextual.

\begin{tabular}{|c|c|c|c|}
\hline Categorias & Contexto doméstico & Contexto externo & Total de codificaçöes \\
\hline Combate à fome e à pobreza & $45 \square$ & 40 & 69 \\
\hline Desigualdade social & 43 & 33 & 59 \\
\hline Mulheres & $31 \square$ & $12 \|$ & $42 \square$ \\
\hline Discriminação & $32 \square$ & 22 & 40 \\
\hline Democracia & $30 \square$ & 14 & $39 \square$ \\
\hline Educação & $27 \square$ & 11 & $35 \square$ \\
\hline Saúde & 20 & $5 \quad \|$ & 22 \\
\hline Instituiçöes e tratados internacionais & 12 & $15-$ & 21 \\
\hline Autodeterminaçăo dos povos & 7 | & 21 & 21 \\
\hline Desenvolvimento & 13 & $-11-$ & 19 \\
\hline \multirow[t]{2}{*}{ Direitos humanos e o mundo virtual } & 71 & 13 & 14 \\
\hline & & & predomináncia \\
\hline Elaboraçăo: SILVA e KLEIN (2016) & & & inter-relaçào \\
\hline
\end{tabular}

Fonte: Adaptado de Silva (2016, p. 203). 
A categoria "mulheres" teve conotação especial no governo Dilma, por ela ter sido a primeira mulher a ser eleita governante do Brasil. O governo buscou manter a mulher como figura central nos programas de distribuição de renda, na promoção da igualdade de oportunidades entre homens e mulheres, no cumprimento da Lei Maria da Penha, no combate ao índice de mortalidade materna e na implantação de políticas de saúde feminina (ROUSSEFF, 2011d). No contexto externo, posicionou-se favoravelmente a que a questão de gênero fosse considerada uma prioridade internacional, principalmente após a criação da ONU Mulheres, abordando questões como o empoderamento feminino e a feminização da pobreza, tanto devido à crise econômica quanto às crises humanitárias.

Na categoria "discriminação", Dilma exaltou a rejeição a qualquer tipo de preconceito ou discriminação, porém reconhecendo a persistência da discriminação na sociedade brasileira. Esse combate às várias faces da discriminação também repercute em nível externo, principalmente em relação à xenofobia nos países europeus decorrente da crise econômica, considerando-a uma violação internacional aos direitos humanos (ROUSSEFF, 2011f).

$\mathrm{Na}$ categoria "democracia" observa-se a relação entre democracia, promoção dos direitos humanos, luta contra a violência e garantia dos direitos dos cidadãos, com Dilma evocando a democracia como meio para a promoção da justiça social e a redução de desigualdades (ROUSSEFF, 2012b), assegurando ambos os direitos civis e sociais. Em nível externo, à relação entre democracia e direitos humanos é adicionado o desenvolvimento econômico e social, com os movimentos sociais ocorridos no norte da África e no Oriente Médio, a Primavera Árabe (ROUSSEFF, 2012c).

Já as categorias "educação" e "saúde" demonstram a atuação obrigatória do governo Dilma no trato doméstico de ambas as políticas, voltadas para o aumento do acesso à educação, por meio de diversos programas educacionais, e a garantia do acesso universal à saúde.

A análise da categoria "autodeterminação dos povos" apresenta predomínio contextual externo, destacando-se o reconhecimento do Estado da Palestina e a defesa de uma solução pacífica do conflito 
com Israel, em especial na busca por um consenso internacional em favor da existência de ambos os Estados (ROUSSEFF, 2013b). A defesa do diálogo como principal elemento para alcançar a paz, do princípio da não intervenção, da defesa da soberania dos povos e do uso da força para a defesa de vidas humanas somente sob o escrutínio dos órgãos multilaterais foram defendidos por Dilma (ROUSSEFF, 2013a; 2013c) como princípios-guia para a solução de conflitos, tais como os ocorridos na Síria, na Ucrânia e entre Israel e Palestina.

Merece destaque o aparecimento da categoria "direitos humanos e o mundo virtual", marcada pelo caso da espionagem norte-americana de informações pessoais de cidadãos e de funcionários do governo brasileiro. Introduzindo a questão do direito à privacidade do indivíduo no ambiente virtual e denunciando a violação à soberania do Brasil, Dilma advertiu para a necessidade do estabelecimento de mecanismos multilaterais capazes de garantir os princípios de liberdade de expressão, respeito aos direitos humanos, universalidade do desenvolvimento social e humano, diversidade cultural (sem imposição de valores) e a neutralidade da rede (ROUSSEFF, 2013b). O predomínio contextual externo dessa categoria ocorreu devido à posição de denúncia nos âmbitos da Assembleia Geral da ONU (na Terceira Comissão) e do Conselho de Direitos Humanos, nos quais foram apresentadas resoluções, ${ }^{26}$ lideradas por Brasil e Alemanha, reconhecendo que os mesmos direitos que as pessoas têm no mundo real (off-line) devem ser protegidos no mundo virtual (on-line).

A inter-relação contextual nas categorias "combate à fome e à pobreza", "desigualdade social", "instituições e tratados internacionais" e "desenvolvimento" é explanada em função da relevância dada às questões sociais pelo governo Dilma, dando prosseguimento à iniciativa do governo Lula de combate às desigualdades sociais e de preocupação com a perspectiva social de desenvolvimento do país.

26 No CDH, Resolução A/HRC/26/L.24 (UN, 2014); e na Assembleia Geral da ONU, Resolução A/RES/69/166 (UN, 2015). 
O combate à fome e à pobreza foi alçado por Dilma como sendo um imperativo do campo dos direitos humanos (ROUSSEFF, $2011 b$ ), além de estimular o desenvolvimento social do país visando sua perspectiva social, por meio da melhoria da renda e de políticas públicas sociais. No âmbito externo, o tópico foi assinalado como sendo um desafio global (ROUSSEFF, 2013b), associando-se também à promoção da paz e ao desenvolvimento sustentável, oferecendo a experiência brasileira para combater a pobreza em países da América Latina e o Caribe, África e Oriente Médio. ${ }^{27}$

Diretamente ligado ao combate à pobreza, a categoria "desigualdade social" expõe a consideração pelo governo da desigualdade social como uma questão de dívida social do Estado com sua população, defendendo a promoção da justiça social em diversos campos, como educação, saúde e ações afirmativas, aumentando as oportunidades aos cidadãos (ROUSSEFF, 2011e). O combate à desigualdade social também ganhou, em nível externo, contorno de crítica aos custos sociais causados pelas medidas de austeridade tomadas, principalmente por países europeus, no combate à crise econômica (ROUSSEFF, 2012a).

A tríade "combate à fome e à pobreza", "desigualdade social" e "desenvolvimento" foi constantemente defendida por Dilma tanto em seus pronunciamentos domésticos quanto externos. É observável um equilíbrio no tratamento dos três temas em nível doméstico e externo devido à intensa inter-relação existente nesse caso: a defesa do combate à fome e à pobreza, somada à defesa do desenvolvimento social.

Já a inter-relação contextual da categoria “instituições e tratados internacionais" pode ser interpretada a partir do posicionamento do governo em externalizar as políticas e os princípios domésticos juntamente com a domesticalização da normativa internacional. Por exemplo, Dilma afirmou que as políticas brasileiras para afrodescendentes

27 Em setembro de 2014, a Organização das Nações Unidas para Alimentação e Agricultura (FAO) reconheceu o cumprimento pelo Brasil da redução da proporção de pessoas com fome, saindo oficialmente do mapa da fome mundial. Porém, desde 2018, a FAO assinala o possível retorno do Brasil a esse mapa devido ao aumento dos índices de pobreza extrema no país (CALVI, 2019). 
expressam o compromisso do país com a declaração e o plano de ação da Conferência Mundial contra o Racismo (Conferência de Durban), apoiando também a resolução do $\mathrm{CDH}$ sobre a incompatibilidade entre democracia e racismo (ROUSSEFF, 2011f).

Dilma apresenta uma percepção dos direitos humanos que equilibra os direitos civis e políticos com os direitos sociais e econômicos, mas dando continuidade à dimensão social da política no campo dos direitos humanos de Lula, ao manter em seu cerne as questões de combate à fome e à pobreza, a busca por justiça social e a defesa de uma rede de proteção às parcelas mais pobres da sociedade, elementos que reverberam a externalização dos princípios e das políticas geridas em nível doméstico pelo governo.

Todavia, Dilma se alinha com suas próprias ideias no campo dos direitos humanos em virtude de sua maior afinidade com a questão, principalmente em relação às mulheres e à democracia. De fato, devido a essa identificação pessoal com as questões, Dilma demonstrou uma atuação interessada na política externa de direitos humanos, com uma atuação própria, mais centrada em seu papel de administradora do país, buscando apresentar à comunidade internacional a realização de seu trabalho, de que está "fazendo o dever de casa”. Um sinal disso é o fato de o entrelaçamento entre os contextos doméstico e externo da política externa de direitos humanos do governo Dilma Rousseff ter sido feito de dentro para fora: a atuação doméstica do Brasil é apresentada em nível internacional como forma de confirmar o cumprimento dos princípios internacionais de proteção e promoção dos direitos humanos, e de legitimar a posição do Brasil como um país em desenvolvimento, respeitador dos direitos humanos, que pode vir a servir de exemplo aos outros países (SILVA, 2016). O quadro 2 sintetiza a análise da política externa do governo Dilma com relação aos direitos humanos realizada a partir da análise de conteúdo de seus pronunciamentos oficiais. 
Quadro 2 - Síntese da análise de conteúdo da perspectiva de Dilma Rousseff sobre os direitos humanos em seu primeiro mandato

\begin{tabular}{|c|c|c|c|}
\hline Presidente & Perspectiva & Comportamento externo & Inter-relação \\
\hline Dilma Rousseff (2011-2014) & $\begin{array}{l}\text { • Responsabilidade do } \\
\text { Estado na proteção aos direitos } \\
\text { humanos e prosseguimento } \\
\text { da sua dimensão social; } \\
\text { • Equilibrio entre a perspectiva } \\
\text { liberal e a dimensão social. }\end{array}$ & $\begin{array}{l}\text { • Direitos humanos como } \\
\text { centro da política externa e } \\
\text { crítica à seletividade do sistema } \\
\text { internacional de direitos humanos; } \\
\text { - Apresentação do conceito } \\
\text { responsabilidade ao proteger; } \\
\text { •Conjuntura da espionagem } \\
\text { norte-americana: direito à privaci- } \\
\text { dade do indivíduo, respeito aos di- } \\
\text { reitos humanos no mundo virtual. }\end{array}$ & $\begin{array}{l}\text { Continuidade da dimensão } \\
\text { social dos direitos humanos, } \\
\text { com a externalização dos prin- } \\
\text { cípios das políticas domésticas. }\end{array}$ \\
\hline
\end{tabular}

Fonte: adaptado de Silva (2016, p. 214-216).

A pesquisa apresentada exemplifica como, a partir de uma estratégia de análise de conteúdo baseada nos objetivos da pesquisa (identificar a percepção, os tópicos e contribuições sobre os direitos humanos de um determinado governo) e nas decisões do/a pesquisador/a (o uso de pronunciamentos oficiais, as categorias criadas e o conteúdo codificado), é possível alcançar resultados empíricos relevantes para a análise de política externa. Assim, por meio da técnica e da utilização do software foram identificados, nos pronunciamentos oficiais de Dilma Rousseff, os trechos referentes ao assunto em questão, os direitos humanos. Além de classificar em categorias analíticas os principais conceitos de tal tema, a pesquisa conseguiu resultados relevantes para apresentar a perspectiva de Dilma com relação ao campo dos direitos humanos e para corroborar a hipótese sobre a politização desse campo da política externa brasileira e sua inter-relação com o contexto político doméstico e os interesses de seus principais atores.

\section{A trajetória do Mercosul e sua tomada de decisões}

$\mathrm{O}$ objetivo inicial da pesquisa foi entender como eram tomadas as decisões dentro do Mercosul, quais decisões eram adotadas, sobre que assuntos, quem as concebia e de que forma. Para isso, traçou-se uma estratégia de pesquisa de análise de conteúdo documental 
de todas as decisões tomadas pelo Conselho Mercado Comum (CMC), principal organismo incumbido das decisões, que acabou resultando em uma base de dados do Mercosul. Nela podem ser facilmente identificadas as decisões tomadas de acordo com três dos critérios utilizados para sua codificação dentro do programa de tratamento de dados NVivo (o mesmo software utilizado pela pesquisa anterior). Nesse sentido, a construção da base transformou-se em um objetivo central do processo de pesquisa, assumindo um caráter holístico, motivo pelo qual as decisões metodológicas adquiriram especial relevância tanto para a validez teórica do processo reflexivo, quanto dos resultados alcançados (ZHAO et al., 2016; GRANJA HERNÁNDEZ, 2016b).

De forma independente da metodologia utilizada (do desenho) e do assunto a ser estudado (do objeto), investigar implica um processo contínuo de reflexão em ciclos interativos de planejamento, implementação, reflexão e revisão (SALMONA; KACZYNSKI, 2016). Esses ciclos da pesquisa foram desenvolvendo-se interativamente através das diferentes fases expostas acima (BARDIN, 2011). Nesse sentido, a construção da estratégia de pesquisa, sua revisão e sua aplicação adquirem contemporaneidade, transformam-se na maneira em como controlamos os resultados de nossas próprias indagações. Uma vez obtidas as fontes da página oficial do Mercosul (documentos com as decisões), ${ }^{28}$ começou-se a fase de pré-análise, a identificação das informações nelas contidas, sua leitura e codificação de acordo com os assuntos tratados (primeiro critério de classificação). A decisão de utilizar análise categorial para a sistematização dos documentos foi precedida por algumas escolhas feitas, muitas vezes, espontaneamente (indução). Na verdade, toda "redução de dados" implica em e deriva de processos automáticos e conscientes por parte do pesquisador (REVUELTA-DOMÍNGUEZ; SÁNCHEZ-GÓMEZ, 2005).

Cada decisão do Mercosul foi adicionada à base de dados como um documento único, classificada segundo o ano em que foi tomada 
e o lugar onde foi a reunião (informação pertinente para a construção da trajetória da decisão, como ela teria sido definida). Posteriormente, as decisões foram codificadas tomando como unidades de registro as linhas do documento.

Além das 960 decisões finais até 2017, foram analisadas as 74 declarações presidenciais realizadas conjuntamente até 2014. Em terceiro lugar, realizou-se uma amostragem seletiva das atas das reuniões especializadas, organismos específicos e foros com que conta o bloco, sendo construída uma amostra de 582 atas de tais reuniões. Elas compõem um universo documental diferente do das decisões, com mais de 5 mil documentos. Seguindo os critérios de disponibilidade e pertinência da informação nelas contida, foram escolhidas 582 atas das reuniões deliberativas e consultivas da Comissão de Comércio (CCM), Grupo Mercado Comum (GMC) e das reuniões especializadas e dos ministros de Estado que compõem o organograma do bloco. Foram analisados, no total, 1.616 documentos, todos de acesso público. A tabela 1 resume o universo documental do banco de dados criado.

Tabela 1 - Universo documental analisado ${ }^{1}$

\begin{tabular}{c|c|c|c|c}
\hline Anos & Decisões & Declarações presidenciais & Atas reuniões & No reuniões \\
\hline 1991 & 16 & - & 11 & 10 \\
\hline 1992 & 11 & - & 13 & 14 \\
\hline 1993 & 13 & - & 15 & 12 \\
\hline 1994 & 29 & 4 & 13 & 23 \\
\hline 1995 & 9 & 4 & 19 & 130 \\
\hline 1996 & 18 & 4 & 16 & 184 \\
\hline 1997 & 26 & 0 & 13 & 199 \\
\hline 1998 & 23 & 2 & 18 & 171 \\
\hline 1999 & 25 & 4 & 15 & 213 \\
\hline 2000 & 70 & 2 & 12 & \\
\hline
\end{tabular}




\begin{tabular}{|c|c|c|c|c|}
\hline Anos & Decisões & Declarações presidenciais & Atas reuniōes & № reuniões \\
\hline 2001 & 16 & 1 & 17 & 208 \\
\hline 2002 & 32 & 2 & 12 & 179 \\
\hline 2003 & 41 & 3 & 13 & 240 \\
\hline 2004 & 55 & 0 & 15 & 237 \\
\hline 2005 & 40 & 3 & 19 & 286 \\
\hline 2006 & 38 & 2 & 21 & 296 \\
\hline 2007 & 62 & 4 & 49 & 374 \\
\hline 2008 & 59 & 6 & 57 & 359 \\
\hline 2009 & 33 & 4 & 27 & 311 \\
\hline 2010 & 67 & 7 & 49 & 398 \\
\hline 2011 & 39 & 5 & 53 & 416 \\
\hline 2012 & 68 & 6 & 44 & 401 \\
\hline 2013 & 18 & 4 & 33 & 349 \\
\hline 2014 & 47 & 7 & 28 & 234 \\
\hline 2015 & 58 & - & - & - \\
\hline 2016 & 10 & - & - & - \\
\hline 2017 & 37 & - & - & - \\
\hline Total & 960 & 74 & 582 & 5.339 \\
\hline
\end{tabular}

Fonte: adaptado de Granja Hernández (2016a, p. 142).

Nota: A análise das decisões do Mercosul é a única tarefa de codificação que foi atualizada até 2017; todas as demais fontes tiveram um período menor, até 2014.

A pesquisa teve três fontes documentais distintas, cada uma sendo considerada uma unidade de análise, ao mesmo tempo que as linhas dos documentos codificados constituem as unidades de registro, o que permitiu fazer análises transversais utilizando diferentes fontes, com unidades de registro compatíveis e comparáveis (linhas do documento). A primeira unidade de análise foram as decisões do Mercosul, a leitura por linhas do documento (unidade de registro) levou à codificação dos fragmentos de texto nas categorias. A segunda unidade de análise foram as atas selecionadas; por fim, 
foram analisadas as declarações presidenciais, com igual codificação. As categorias codificadas nas diferentes unidades de análise foram fundamentalmente as mesmas, pelo que, a partir de sua comparação, podem-se identificar padrões de co-ocorrência de categorias entre unidades de análise e critérios de codificação diferentes.

Os três critérios utilizados para a classificação e codificação das 960 decisões tomadas pelo CMC até 2017 são: 1) os assuntos dos quais tratavam as decisões (análise temática); 2) os objetivos propostos pelos diferentes governos ao momento de tomá-las; e 3) a maneira como as decisões eram tomadas (identificação do país proponente e das diferentes reações dos parceiros de bloco). Esses critérios se transformaram em várias categorias de análise (360 exatamente), em que foram codificados os trechos (ou porções do texto) de acordo com os temas tratados (critério 1) e com os objetivos expressos em sua proposta e durante as negociações (critério 2). Os diferentes assuntos tratados adquiriram a etiqueta do tema principal da decisão. O Gráfico 2 resume alguns dos resultados da pesquisa que ajudam a entender melhor o processo de tomada de decisão do Mercosul.

O gráfico mostra a inconstância na quantidade total de decisões tomadas por ano, devido às assimetrias e à rotatividade nas presidências do bloco: ${ }^{29}$ os países maiores têm mais iniciativas e logram mais facilmente consensos para tomar decisões e controlar a agenda nos momentos em que detêm a presidência pro tempore. Embora ao longo do tempo a quantidade de decisões tenda a aumentar, a evidência de momentos críticos para o funcionamento do bloco (2001, a raiz da crise argentina, 2013, a partir da crise política no Paraguai, e em 2016, a brasileira) e a maior ou menor convergência ideológica entre os governos dos Estados partes podem explicar a quantidade de decisões tomadas em cada ano. A partir do auge dos governos de esquerda na região, ${ }^{30}$ com a consequente convergência ideológica entre eles,

29 A presidência do Mercosul se exerce rotativamente por seis meses entre todos os países membros.

30 Existem distintas conceitualizações para se referir ao período de predominância de governos de esquerda na região, entre elas, a denominada "maré rosa" (PANIZZA, 2006, 2009) identifica diferenças ideológicas e práticas entre os distintos governos; outras conceitualizações preferem se referir a governos progressistas (LIMA, 2008) e não identificam tantas coincidências ideológicas, a não ser a de se opor ao neoliberalismo como doutrina econômica. Uma análise detalhada das diferentes práticas governamentais, assim como de suas diferenças ideológicas e formas de conceitualizar tais governos, pode ser consultada em Silva $(2009,2010)$. 
observamos um aumento constante na quantidade de assuntos que ingressam na agenda do bloco, que decresce para o final do período de análise, quando tal convergência diminui, abrindo espaço para uma nova convergência ideológica mais à direita do espectro, que pode ser identificada como neoliberal.

Gráfico 2- Evolução da tomada de decisões do Mercosul, por assuntos tratados (19912017)

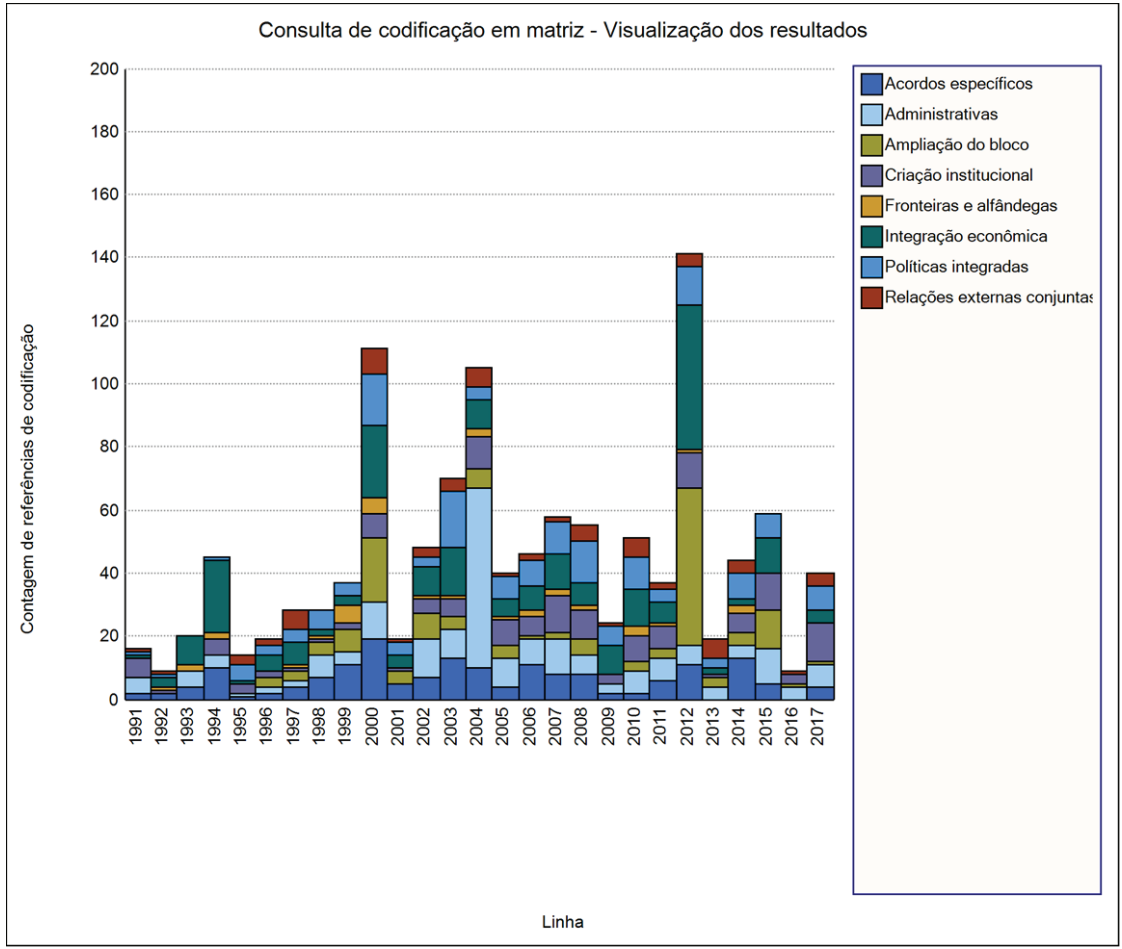

Fonte: decisões do Mercosul disponíveis em http://www.mercosur.int Elaboração própria.

Há também vários assuntos que se mantêm presentes na agenda do Mercosul ao longo do tempo, embora com diferentes ênfases. A “integração econômica” é um exemplo: no período de convergência neoliberal dos governos da região (1991-1998), ela é a categoria 
mais codificada; já no período de convergência dos governos de esquerda, perde tal protagonismo. Vemos que, apesar de ter perdido a relevância discursiva na retórica das declarações presidenciais, o assunto da "integração econômica" permanece constante no tratamento do bloco. Somados aos "acordos específicos", visto que boa parte deles são referidos ao comércio setorial e de serviços, vemos que o interesse em uma integração puramente comercial está presente em todo o período estudado. Atualmente, vemos uma retomada da importância do assunto na agenda do Mercosul, embora tenha havido uma redução do termo a uma mera integração comercial. Inclusive, com a assinatura do acordo com a União Europeia, pode se dizer que o Mercosul alcança um velho objetivo traçado durante o período da convergência ideológica entre os governos neoliberais da década de 1990.

Resumidamente, ao longo do tempo, temos várias decisões tomadas em torno de aspectos específicos do funcionamento do bloco (categoria "administrativas" no Gráfico 2). A "criação institucional" também tem sido um esforço de caráter permanente na agenda do Mercosul, com um aumento importante de decisões codificadas sobre tal assunto no período de convergência ideológica entre os governos de esquerda. A “criação institucional” teve certa relevância em 1994 (quando assinado o Protocolo de Ouro Preto, que especifica a estrutura interna minimalista do Mercosul) e alcança um nível sem precedentes em 2010, quando a convergência ideológica entre os governos assume a importância de ter instituições mais fortes dentro do bloco e são criados os institutos e reuniões ministeriais setoriais com caráter consultivo. Poder-se-ia pensar que os assuntos vinculados ao funcionamento interno do bloco continuam na agenda, mas com uma ênfase oposta, já que as instituições criadas no período anterior vêm sendo objeto de um processo de redução ou de estrangulamento orçamentário no conteúdo das decisões codificadas a partir de 2015.

Outro dos assuntos que permaneceram na agenda das decisões tomadas no Mercosul são as questões fronteiriças e alfandegárias (neste último caso, há uma presença constante na agenda das 
questões relativas à Tarifa Externa Comum). Por sua vez, as decisões codificadas como "relações exteriores de bloco" tiveram a especificidade de ter acompanhado a trajetória de codificação das decisões econômicas, já que procuravam novos mercados durante todo o período, embora com distintas estratégias de ação - nesse sentido, é interessante a estratégia de promoção de exportações conjuntas que se instaurou durante a convergência de governos progressistas. Tal categoria também assinala a procura e construção de posicionamentos conjuntos nos âmbitos multilaterais. Já o assunto do alargamento do Mercosul para outros Estados vizinhos, embora sempre estivesse na agenda, como se vê na categoria "Estados associados", alcançou um auge em 2012, quando a adesão como membros associados chegou a toda América do Sul, mas se viu diminuída a partir da crise da Venezuela e suas consequências ao querer atuar como membro permanente do bloco.

No entanto, certos assuntos têm adquirido maior relevância ao longo do tempo, aumentando sua ênfase conforme a institucionalização do bloco aumenta e a convergência ideológica entre os governos do Mercosul alcança certos patamares. Tais assuntos referem-se à “integração de políticas”, que cresce a partir de 2003 e nucleia todos os esforços por integrar políticas públicas do período, nas áreas de educação, integração produtiva, segurança, construção de cidadania e difusão e promoção de direitos humanos.

O segundo critério para a codificação referia-se aos objetivos dos governos dos Estados parte. Este critério teve uma construção teórico-conceitual fundamentada em um dos argumentos da tese, o intergovermentalismo como base do consenso. De fato, o Mercosul é um processo de integração intergovernamental, característica que tem sido amplamente debatida e criticada pela literatura, ${ }^{31}$ consequentemente são os diferentes governos (e não uma instituição de caráter supranacional) que compartilham a responsabilidade da tomada de decisões. Além disso, existe a necessidade de criar consenso para tomar uma decisão dentro do Mercosul. Isso quer

31 Ver Malamud (2003, 2010) e Caetano, Ventura e Vázquez (2009). 
dizer que se impõe uma regra de unanimidade sobre o processo decisório em que o timing na aprovação e a inovação institucional têm um protagonismo real para que uma decisão seja finalmente tomada. Uma vez que um determinado assunto chega na agenda, ele pode estar sendo debatido, permanecer lá sem ser sequer tocado, ou não ser tomada nenhuma decisão a seu respeito durante muito tempo, até alcançar o consenso necessário para tal. Este tipo de mecanismo tem gerado várias críticas por parte dos especialistas, os quais entendem, inclusive, que este promove paralisia decisória. Pelo contrário, a pesquisa argumenta a favor das práticas e mecanismos para a construção de consensos existentes dentro do bloco como uma de suas contribuições inovadoras, já que, apesar das travas impostas a partir do timing nas negociações, e do poder de veto que têm os Estados, também vemos práticas de negociação reduzidas a experts que se desenvolveram nos organismos criados durante o período, quando são decididos os conteúdos das decisões do Mercosul.

A codificação dos objetivos dos governos gerou a necessária procura de outras fontes que poderiam suprir o vazio de informação que possuíam as decisões do Mercosul já tomadas (documentos finais), quando tais objetivos não eram explícitos nas "motivações” das decisões, e quando não continham nenhuma informação acerca do seu processo decisório, por exemplo, qual país, governo ou ator tinha tomado a iniciativa de propor na agenda e como se tinha alcançado o consenso necessário para transformar tal assunto em uma decisão tomada (critério 3). Assim foi como, ao escopo inicial de documentos (universo de decisões tomadas pelo CMC), foram somadas as atas das reuniões dos organismos competentes, compondo um segundo escopo de 1.522 documentos. Este segundo grupo de fontes analisadas foi categorizado e codificado no intuito de entender o processo decisório do bloco em sua totalidade.

A tomada de decisões do Mercosul tem características singulares: a unanimidade requisitada para alcançar uma decisão (consenso); o poder da iniciativa na agenda concentrado nas presidências pro tempore (PPT); e o escalonamento do processo decisório entre 
diferentes instituições e órgãos deliberativos e consultivos. Por tais motivos, a seleção do segundo grupo de fontes documentais foi feita após a reconstrução do processo decisório do Mercosul, que constituiu parte importante da estratégia empregada para a seleção dos documentos complementares a serem colocados dentro da base de dados. Sem a informação prévia de quais tinham sido as decisões tomadas, não se poderia ter acesso nas atas aos dados sobre como foram as negociações, pelo que tal processo implicou uma mudança no desenho da pesquisa, embora não da estratégia. Houve a necessidade de adicionar mais documentação do que primeiramente se pensou em analisar. Fez-se uma amostragem seletiva do tipo de informação contida nas atas de todas as reuniões dos grupos, organismos dependentes e especializados para saber se efetivamente contavam com a informação necessária para entrar na base de dados ou não (critério de pertinência). Tal seleção privilegiou a presença de informação sobre o país que tinha apresentado a iniciativa e as diferentes reações a ela durante as negociações antes de dar continuidade ao processo decisório.

Dessa forma, a análise de conteúdo permitiu saber mais sobre o processo decisório do Mercosul, além de estabelecer hipóteses sobre o relacionamento intergovernamental e a maior ou menor convergência ideológica entre eles. Também forneceu evidência empírica sobre os assuntos mais relevantes, assim como sobre os que têm se mantido em forma constante dentro da agenda, os que aparecem de acordo com os distintos períodos e os que não têm permanência ou interesse por parte dos governos implicados. A pesquisa tem um argumento central baseado nas evidências encontradas a partir da análise de conteúdo. Nesse sentido se desvelou o processo decisório do Mercosul pensando na construção de uma base de dados em que pudessem ser identificados: os assuntos tratados ao longo do tempo, que atores tiveram as iniciativas, qual foi o relativo sucesso ou fracasso das propostas (não sua aplicação final, mas sua trajetória desde que foi colocada na agenda) e as diferentes estratégias de ação construídas para sua aprovação no CMC. Concomitantemente, foi possível estabelecer hipóteses sobre o regionalismo e sua vertente 
comercialista e política, além de reflexões sobre o funcionamento do Mercosul dependente de suas instituições próprias, como a necessidade do consenso para a tomada de decisões, o poder de veto e de agenda setting a partir das presidências pro tempore.

\section{Reflexões finais}

O presente artigo pretende contribuir em dois sentidos para as pesquisas sobre política externa: em primeiro lugar, privilegia a técnica da análise de conteúdo para gerar pesquisas com qualidade empírica. Assim, identifica as diferentes escolas e processos que se têm desenvolvido ao longo do tempo para se posicionar claramente a favor da dependência entre o objeto, os objetivos, o desenho teórico-argumental e a subjetividade do/a pesquisador/a na aplicação de análises de conteúdo. Nesse sentido, defende a técnica e celebra a propagação de pesquisas na área que sejam transparentes em seus aspectos metodológicos para contribuir ainda mais para o desenvolvimento de tal ferramenta analítica.

Em segundo lugar, a exemplificação da utilização de diferentes estratégias de análises de conteúdo a partir das pesquisas descritas brinda o leitor com as ferramentas-chave para entender como se constrói uma estratégia de pesquisa que gere resultados empíricos para testar argumentos no campo política externa e regionalismo. No processo, são apresentados dados detalhados e inabaláveis sobre as especificidades da política externa brasileira de direitos humanos, assim como o resultado do processo de negociação das decisões do Mercosul. Ambas as pesquisas demonstram como a análise de conteúdo consiste em uma ferramenta metodológica eficaz, sobretudo ao dispor de dados quantitativos e qualitativos que reverberam os resultados alcançados, atendendo às necessidades metodológicas e conseguindo oferecer respostas às perguntas das respectivas pesquisas.

As pesquisas explanadas também corroboram com o argumento central do presente artigo, de que a técnica de análise de conteúdo é plural, não é única, devido a sua pluralidade de aplicação, decorrente 
do desenho e da estrutura da pesquisa, bem como das escolhas e dos trade offs assumidos pelos pesquisadores.

Por outro lado, as abordagens teóricas de cada pesquisa correlacionaram-se com a análise de conteúdo, influenciando desde a criação das categorias de análise até os objetivos em si das pesquisas, como a análise da inter-relação contextual dos pronunciamentos oficiais para corroborar com a perspectiva teórica da interação entre os contextos doméstico e externo na identificação de problemas e na definição das medidas governamentais tomadas. Analisar o conteúdo dos pronunciamentos também forneceu material empírico para endossar a perspectiva de que as ideias dos atores encarregados da tomada de decisão - no caso da pessoa que exercia o cargo de presidente da República - impactam na definição e/ou mudança dos objetivos governamentais desses atores. As categorias criadas identificaram e mostraram em detalhes os principais tópicos políticos no campo dos direitos humanos e sua vinculação com a política externa brasileira.

Essa constatação também se aplica à análise de que os países maiores do bloco teriam mais poder de negociação nas instâncias mercosulinas de tomada de decisão. Confirmou-se que o processo de construção das categorias de análise pode ser feito ao longo da pesquisa e, embora partindo de pressupostos teoricamente estabelecidos, a metodologia escolhida pode modificar tais acepções prévias no transcurso da análise empírica, sobretudo quando não se conhece previamente o escopo documental que será objeto da análise de conteúdo.

Por fim, é importante destacar que a escolha da técnica da análise de conteúdo textual e documental, sejam documentos normativos ou pronunciamentos, pode apresentar limitações (pertinência e acessibilidade da informação relevante, por exemplo), o que implica no permanente trade off entre as escolhas dos pesquisadores em função dos objetivos propostos inicialmente e as diferentes técnicas de análise. Nesse sentido, o crescente desenvolvimento de softwares e ferramentas de análise abre o leque de opções de que as pesquisas podem se nutrir, ampliando também as possibilidades de aplicação da própria análise de conteúdo, dada sua versatilidade metodológica. 


\section{Referências}

AGGARWAL, Charu; ZHAI, ChengXiang. An introduction to text mining. In: AGGARWAL, Charu; ZHAI, ChengXiang (ed.). Mining text data. New York: Spring Science \& Business Media, 2012, p. 1-10.

BARDIN, Laurence. Análise de conteúdo. São Paulo: Edições 70, 2011.

CAETANO, Gerardo; VENTURA, Deisy; VÁZQUEZ, Mariana. Reforma institucional del Mercosur: análisis de un reto. In: CAETANO, Gerardo (coord.). La reforma institucional del Mercosur: del diagnóstico a las propuestas. Montevideo: Trilce, 2009. p. 21-76.

CAETANO, Gerardo. Mercosur 20 años. Montevideo: Centro de Formación para la Integración Regional (CEFIR), 2011, p. 196.

CALVI, Pedro. O curto caminho de volta ao Mapa da Fome. Brasília: Câmara dos Deputados, 25 abr. 2019. Disponível em: https://www2.camara.leg.br/atividade-legislativa/comissoes/ comissoes-permanentes/cdhm/noticias/o-curto-caminho-devolta-ao-mapa-da-fome. Acesso em: 7 fev. 2020.

CAPPELLE, Mônica Carvalho Alves; MELO, Marlene Catarina de Oliveira Lopes; GONÇALVES, Carlos Alberto. Análise de conteúdo e análise de discurso nas Ciências Sociais. Organizações Rurais e Agroindustriais - Revista de Administração da UFLA, v. 5, n. 1, p.1-15, 2003.

CASTELLS, Manuel. La era de la Información: la sociedad red. 2. ed. Barcelona: Alianza, 2000. v. 1.

CHAORASIYA, Vinay; SHRIVASTAVA, Aparajit . A survey on big data: techniques and technologies. International Journal of Research and Development in Applied Science and Engineering, v. 8, n. 1, 2015.

CHIZZOTTI, Antonio. Pesquisa qualitativa em ciências humanas e sociais. 5. ed. Rio de Janeiro: Vozes, 2013. 
COX, Michael; ELLSWORTH, David. Application-controlled demand paging for out-of-core visualization. In: CONFERENCE ON VISUALIZATION, 8., Phoenix, AZ, out. 1997. Proceedings [...] Washington: IEEE, 1997.

DONTHA, Ramesh. Who came up with the name Big Data? Data Science Central, 2017. 13 jan. 2017. Blog pessoal. Disponível em: https:/www.datasciencecentral.com/profiles/blogs/who-cameup-with-the-name-big-data. Acesso em: 13 jul. 2019.

GRANATO, Leonardo. Brasil, Argentina e os rumos da integração. O Mercosul e a UNASUL. Curitiba: Appris, 2015, 268.

GRANJA HERNÁNDEZ, Lorena. El Mercosur y sus asimetrías: un análisis empírico de la bilateralización. 2016. 378 p. Tese (Doutorado em Ciência Política) - Universidade do Estado do Rio de Janeiro, Rio de Janeiro, 2016a.

GRANJA HERNÁNDEZ, Lorena. La toma de decisiones en el Mercosur, un análisis empírico de las decisiones del CMC. In: ENCUENTRO LATINOAMERICANO DE METODOLOGÍA DE LAS CIENCIAS SOCIALES (ELMeCS), 5., Mendoza, 2016. Actas [...]. Mendoza: ELMECS-UNCuyo, 2016b. p. 1-32. Disponível em: http://elmecs.fahce.unlp.edu.ar/v-elmecs/actas2016/GranjaHernandez.pdf/view?searchterm=None. Acesso em: 12 jan. 2020.

HERMANN, Charles F. Changing course: when governments choose to redirect foreign policy. International Studies Quarterly, v. 34, n. 1, p.3-21, 1990.

HOLSTI, Ole R. Content analysis for the social sciences and humanities. Boston, MA: Addison-Wesley, 1969.

KEOHANE, Robert O.; GOLDSTEIN, Judith. Ideas and foreign policy: an analytical framework. In: KEOHANE, Robert O., GOLDSTEIN, Judith. Ideas and foreign policy: beliefs, institutions, and political change. Nova York: Cornell University Press, 1993. cap. 1, p. 3-30.

KFURI, Regina. O Mercosul e o regionalismo multifacetado na América do Sul. Tese (Doutorado em Ciência Política) Universidade do Estado do Rio de Janeiro, Rio de Janeiro, 2015. 
KRIPPENDORFF, Klaus. Content analysis: an introduction to its methodology. 2. ed. Thousand Oaks: Sage Publications, 2004. cap. 2 , 3 e 5 .

LASSWELL, Harold. The theory of political propaganda. The American Political Science Review, v. 21, n. 3, p. 627-631, ago. 1927.

LIMA, Maria Regina Soares de. Desempenho dos governos progressistas do cone sul: agendas alternativas ao neoliberalismo. Rio de Janeiro: Iuperj, 2008.

LUCAS, Christopher et al. Computer-assisted text analysis for comparative politics. Political Analysis, n. 23, p. 254-277, 2015.

LUSTIG, Carola. Soft or hard power? Discourse patterns in Brazil's foreign policy toward South America. Latin American Politics and Society, n. 58, p.103-125, 2016.

MALAMUD, Andrés. La diplomacia presidencial y los pilares institucionales del Mercosur: un examen empírico. Relaciones Internacionales, v. 15, p.113-138, 2010.

MALAMUD, Andrés. Presidentialism and Mercosur: a hidden cause for a successful experience. In: LAURSEN, Finn (ed.). Comparative regional integration: theoretical perspectives. Ashgate: Aldershot, 2003, p.53-73.

MARIANO, P. Marcelo. A Política Externa Brasileira, Itamaraty e o Mercosul. Tese (Doutorado em Sociologia) -Universidade Estadual Paulista, São Paulo, 2007.

MILNER, Helen. V. Interests, institutions and information: domestic politics and international relations. Princeton: Princeton University Press, 1997.

NETO, Octávio. A. De Dutra a Lula. A condução e os determinantes da política externa brasileira. Rio de Janeiro: Elsevier, 2012, p. 224. NEUENDORF, Kimberly. A. The content analysis guidebook. Thousand Oaks: Sage Publications, 2002.

O'NEIL, Cathy. Weapons of math destruction. How big data increases inequality and threatens democracy. New York: Broadway Books, 2016. cap. 5 e 10. 
O'REILLY, Tim.; MOUGALAS, R. What is web 2.0? Sebastopol, CA: O’Reilly, 30 set. 2005. Disponível em: https://www.oreilly. $\mathrm{com} / \mathrm{pub} / \mathrm{a} / \mathrm{web} 2 / \mathrm{archive} /$ what-is-web-20.html. Acesso em: $1^{\mathrm{o}}$ jul. 2019.

PANIZZA, Francisco. La marea rosa. Análise de Conjuntura OPSA, n. 8, 2006.

PANIZZA, Francisco. Nuevas izquierdas y democracia en América Latina. Revista CIDOB d'Afers Inrernacionals, n. 85-86, p. 75-88, 2009.

PATGIRI, Ripon; AHMED, Arif. Big data: the V's of the game changer paradigm. In: INTERNATIONAL CONFERENCE ON HIGH PERFORMANCE COMPUTING AND COMMUNICATIONS, 18., Sydney, 12-14 dez. 2016. Proceedings [...] Washington: IEEE, 2017. Disponível em: https://dblp.org/db/conf/hpcc/ hpcc2016.html. Acesso em: 15 mar. 2019.

PATRIOTA, Antonio. Continuar não é repetir. [Entrevista a] Paulo Celso Pereira. Veja, 9 jul. 2011. Disponível em: http://www. itamaraty.gov.br/index.php?option=com_content\&view=article \&id=4573: continuar-nao-e-repetir-veja-09-01-2011\&catid=195 \&Itemid=455\&lang=pt-BR. Acesso em: 7 maio 2015.

REVUELTA-DOMÍNGUEZ, Francisco Ignacio; SÁNCHEZGÓMEZ, Maria Cruz. Programas de análisis cualitativo para la investigación en espacios virtuales de formación. Salamanca: Ediciones Universidad de Salamanca, 2005.

ROCHA, Leonardo Caetano da; CARLOMAGNO, Márcio C. Como criar e classificar categorias para fazer análise de conteúdo: uma questão metodológica. Revista Eletrônica de Ciência Política, v. 7, n. 1, p.173-188, 2016.

ROUSSEFF, Dilma. Discurso durante cerimônia de formatura da Turma 2009-2011 do Instituto Rio Branco. Brasília: 20 abr. 2011 a.

ROUSSEFF, Dilma. Discurso durante cerimônia de lançamento do Plano de Superação da Extrema Pobreza - Brasil sem Miséria. Brasília: 2 jun. 2011b. 
ROUSSEFF, Dilma. Discurso durante cerimônia de sanção do projeto de Lei que garante o acesso a informações públicas e do projeto de Lei que cria a Comissão Nacional da Verdade. Brasília: 18 nov. 2011c.

ROUSSEFF, Dilma. Discurso durante Colóquio de Alto Nível sobre Participação Política de Mulheres. Nova York: 19 set. $2011 d$.

ROUSSEFF, Dilma. Discurso durante Compromisso Constitucional perante o Congresso Nacional. Brasília: $1^{\circ}$ jan. 2011e.

ROUSSEFF, Dilma. Discurso no encerramento da reunião de chefes de Estado e de Governo do Encontro Iberoamericano de Alto Nível em Comemoração do Ano Internacional dos Afrodescendentes. Salvador: 19 nov. 2011 f.

ROUSSEFF, Dilma. Discurso durante cerimônia de celebração do

Natal dos catadores e da população em situação de rua. São Paulo: 21 dez. 2012a.

ROUSSEFF, Dilma. Discurso durante cerimônia de posse da Ministra-Chefe da Secretaria de Políticas para as Mulheres, Eleonora Menicucci. Brasília: 10 fev. 2012 b.

ROUSSEFF, Dilma. Discurso na abertura da $67^{\text {a }}$ Assembleia Geral das Nações Unidas. Nova York: 25 set. 2012c.

ROUSSEFF, Dilma. Palestra proferida pela Presidenta da República, Dilma Rousseff, na Harvard Kennedy School of Government. Boston: 10 abr. 2012d.

ROUSSEFF, Dilma. Declaração à imprensa após cerimônia de assinatura de atos com o Presidente do Egito, Mohamed Morsi. Brasília: 8 maio 2013a.

ROUSSEFF, Dilma. Discurso na abertura do Debate Geral da $\mathbf{6 8}^{\mathrm{a}}$ Assembleia-Geral das Nações Unidas. Nova York: 24 set. 2013 b. ROUSSEFF, Dilma. Discurso na cerimônia de posse do Ministro de Estado das Relações Exteriores, Luiz Alberto Figueiredo Machado. Brasília: 28 ago. 2013c. 
ROUSSEFF, Dilma. Cerimônia de formatura da turma 2012-2014 do Instituto Rio Branco e de imposição de insígnias da Ordem de Rio Branco. Brasília: 30 abr. 2014.

SANTOS, Pablo Victor Fontes; OLIVEIRA, Alana Camoça Gonçalves de. Diplomacia pública e mídia: um panorama comparativo dos governos Lula (2003-2010) e o governo Dilma (2011-2014) a partir da análise de conteúdo de discursos oficiais de política externa brasileira. In: ENCONTRO NACIONAL ABRI, 5., Belo Horizonte, 2015. Anais [...]. Belo Horizonte: ABRI, 2015. Disponível em: http://www.encontronacional2015. abri.org.br/site/anaiscomplementares?AREA=14\%20. Acesso em: $1^{\circ}$ ago. 2015.

SILVA, Danielle Costa. A agenda de direitos humanos na política externa brasileira e a participação das ONGs no seu processo de formulação. 2016, 363 p. Tese (Doutorado em Ciência Política) - Universidade do Estado do Rio de Janeiro, Rio de Janeiro, 2016.

SILVA, Fabrício Pereira. Até onde vai a "onda rosa"? Análise de Conjuntura OPSA, Rio de Janeiro, n. 2, fev. 2010.

SILVA, Fabrício Pereira. Vitórias na crise. Trajetórias das esquerdas latino-americanas contemporâneas. 2009, 284 p. Tese (Doutorado em Ciência Política) - Instituto Universitário de Pesquisa do Rio de Janeiro, Rio de Janeiro, 2009.

SALMONA, Michelle; KACZYNSKI, Dan. Don't blame the software: using qualitative data analysis software successfully in doctoral research. Forum: Qualitative Social Research, v. 17, n. 3, p. 1-23, 2016.

UN - UNITED NATIONS. Human Rights Council. A/RES/69/166. Nova York: UN, 20 jun. 2014. Disponível em: https://documentsdds-ny.un.org/doc/UNDOC/LTD/G14/059/67/PDF/G1405967. pdf?OpenElement. Acesso em: 7 fev. 2020.

UN - UNITED NATIONS. General Assembly. A/RES/69/166. Nova York: UN, 10 fev. 2015. Disponível em: http://www.un.org/ en/ga/search/view_doc.asp?symbol=A/RES/69/166. Acesso em: 7 fev. 2020. 
VILELA, Elaine; NEIVA, Pedro. Temas e regiões nas políticas externas de Lula e Fernando Henrique: comparação do discurso dos dois presidentes. Revista Brasileira de Política Internacional, v. 54, n. 2, p.70-96, 2011.

ZHAO, Pengfei et al. Methodological tool or methodology? Beyond instrumentality and efficiency with qualitative data analysis software. Forum: Qualitative Social Research, v. 17, n. 2, p. 1-21, 2016.

\section{Resumo}

O artigo apresenta, em primeiro lugar, uma abordagem inovadora da análise de conteúdo, a partir da ampla concepção da técnica, para demonstrá-la como uma estratégia essencialmente dependente do objeto de pesquisa e das diferentes escolhas feitas pelo/a pesquisador/a. Em segundo lugar, o artigo resgata duas pesquisas de doutorado desenvolvidas com diferentes estratégias de análise de conteúdo para ilustrar os argumentos metodológicos da primeira parte. No transcurso, expõem-se os principais resultados das pesquisas escolhidas tentando evidenciar a construção de dados, e são expostos importantes insights sobre a política externa brasileira e a integração regional sul-americana. Finalmente, ressaltam-se algumas reflexões sobre a pertinência do uso da análise de conteúdo na área de Relações Internacionais, disciplina em que tal ferramenta analítica não tem apresentado um desenvolvimento crescente, se comparada com seu uso na Ciência Política.

Palavras-chave: Análise de conteúdo. Metodologia. Política externa brasileira. Direitos humanos. Integração regional. Mercosul.

\section{Abstract}

The paper presents an innovative approach to using content analysis as a methodological tool, showing how much this approach depends both on the object of research and on the researcher's choices. The article examines two doctoral studies that used different content analysis strategies, highlighting their methodological decisions in the context of different research objectives. In the process, the article presents research results that demonstrate how data were constructed. The paper presents important results and insights made by doctoral studies in the areas of foreign policy and South American regional integration. It also reflects on 
the use of content analysis in International Relations, an area which this analytical tool has not developed as much as in Political Science.

Keywords: Content analysis. Methodology. Brazilian foreign policy. Human rights. Regional integration. Mercosul.

\section{Resumen}

El artículo presenta, primeramente, un abordaje inovador del análisis de contenido, a partir de una concepción amplia de la técnica para mostrarla como una estrategia esencialmente dependiente del objeto de estudio y de las diferentes elecciones hechas por el/la investigador/a. En segundo lugar, el artículo rescata dos investigaciones de doctorado desarrolladas con diferentes estrategias de análisis de contenido para ilustrar los argumentos metodológicos de la primera parte. En ese transcurso, se exponen los principales resultados de las investigaciones en cuestión, intentando evidenciar la construcción de los datos, también son evidenciados importantes insights sobre la política exterior brasileña y la integración regional sudamericana. Finalmente, se resaltan algunas reflexiones sobre la pertinencia del uso del análisis de contenido en el área de Relaciones Internacionales, disciplina en la que tal herramienta analítica no ha presentado un desarrollo tan creciente, cuando comparada con el uso que le han dado en la Ciencia Política.

Palabras clave: Análisis de contenido. Metodología. Política exterior brasileña. Derechos humanos. Integración regional. Mercosur.

Recebido em 14 de janeiro de 2019

Aprovado em 17 de julho de 2020 